\title{
Higher dietary fat quality is associated with lower anxiety score in women: a cross-sectional study
}

\author{
Fatemeh Fatemi ${ }^{1}$, Fereydoun Siassi ${ }^{1 *}$, Mostafa Qorbani $^{2,3^{*}}$ and Gity Sotoudeh ${ }^{1 *}$
}

\begin{abstract}
Background: The relationship between anxiety and dietary fat quality (DFQ) has not been well studied. The aim of this study was to investigate the relationship between anxiety disorder and fatty acids' intake in women.

Methods: This cross-sectional study included 300 women aged 18-49 attending healthcare centers. Dietary exposure was measured by a 168-item semi-quantitative food frequency questionnaire (FFQ). To determine the status of anxiety, the Depression, Anxiety, and Stress Scale (DASS) questionnaire was used. Based on the total score of anxiety, the participants were divided into two groups of without anxiety $(<8)$ and with anxiety $(\geq 8)$. The relationship between fatty acids intake and odd ratio (OR) for anxiety was analyzed by simple logistic regression.
\end{abstract}

Results: About $37.7 \%$ of individuals reported anxiety. After adjustment for covariates, an increase in the OR for anxiety was observed across the quintuples of saturated fatty acids (SFAs) (OR 3.17; 95\% Cl 1.43-7.00; $p$-trend $=0.005)$. In addition, higher intakes of monounsaturated fatty acids (MUFAs) (OR 0.15; 95\% Cl 0.05-0.44; $p$-trend $=0.001$ ), oleic acid (OR 0.25; 95\% Cl 0.09-0.67; $p$-trend =0.002), alpha-linolenic acid (ALA) (OR 0.07; 95\% Cl 0.02-0.23; $p$-trend <0.001), and $n-3: n-6$ poly unsaturated fatty acids (PUFAs) (OR 0.56;95\% Cl 0.24-1.03; $p$-trend $=0.02)$ were found to be related with lower OR of anxiety.

Conclusion: Intake of SFAs was positively related to anxiety disorder, whereas MUFAs, oleic acid, ALA, and n-3: n- 6 PUFAs intake were inversely related to anxiety score. For investigating the association of fat intake and anxiety disorder, DFQ may be a useful measure.

Keywords: Anxiety disorder, Dietary fat quality, Fatty acids

\section{Introduction}

According to the World Health Organization's (WHO) report, anxiety is one of the most common psychiatric disorders [1]. The global prevalence of anxiety has been reported $11.4 \%$ [2]. This disorder is more common in

\footnotetext{
*Correspondence: siassif@tums.ac.ir; mqorbani1379@yahoo.com; gsotodeh@tums.ac.ir

${ }^{1}$ Department of Community Nutrition, School of Nutritional Sciences and Dietetics, Tehran University of Medical Sciences, Hojatdost street, Naderi street, Keshavarz Blv., Tehran, Iran

${ }^{2}$ Non-Communicable Diseases Research Center, Alborz University of Medical Sciences, Karaj, Iran

Full list of author information is available at the end of the article
}

women than men [3]. The prevalence of anxiety in individuals with more than 14 years of age in Iran has been reported $15.2 \%$ (18.3\% in women and $10.8 \%$ in men) [4]. Anxiety disorders are significantly related to poor social relationships [5] and physical conditions such as heart disease [6], gastrointestinal disease [7], migraine headache [8], thyroid disease [9], depression, and stress [10, $11]$.

Lipids play an important role in the function of neurons in the brain [12]. Neuronal cell membranes have high content of polyunsaturated fatty acids (PUFAs), especially docosahexaenoic acid (DHA), which are important for development, maintenance, and function

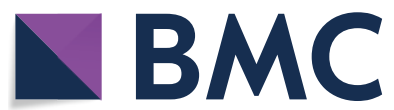

(c) The Author(s) 2020. This article is licensed under a Creative Commons Attribution 4.0 International License, which permits use, sharing, adaptation, distribution and reproduction in any medium or format, as long as you give appropriate credit to the original author(s) and the source, provide a link to the Creative Commons licence, and indicate if changes were made. The images or other third party material in this article are included in the article's Creative Commons licence, unless indicated otherwise in a credit line to the material. If material is not included in the article's Creative Commons licence and your intended use is not permitted by statutory regulation or exceeds the permitted use, you will need to obtain permission directly from the copyright holder. To view a copy of this licence, visit http://creativecommons.org/licenses/by/4.0/. The Creative Commons Public Domain Dedication waiver (http://creativecommons.org/publicdomain/zero/1.0/) applies to the data made available in this article, unless otherwise stated in a credit line to the data. 
of the nervous system. These fatty acids are involved in membrane fluidity, which is important for synaptic transmission and function of membrane proteins and neurotransmitters such as serotonin and dopamine [13-15]. Lack of $n$-3 PUFAs in the brain may lead to depressionand anxiety- associated behaviors [12]. A meta-analysis found that, compared with the control group, subjects with social anxiety disorders had lower blood levels of n-3 PUFAs, eicosapentaenoic acid (EPA) and DHA, and/ or higher levels of $n-6$ PUFA, arachidonic acid (ARA) [16]. Lower $n-3: n-6$ PUFAs ratio and higher saturated fatty acids (SFAs):monounsaturated fatty acids (MUFAs) ratio may have adverse effects on the membrane fluidity $[17,18]$. In mice, a reduction of MUFAs in the hippocampus resulted in alterations in cell membrane fluidity and loss of memory, learning disability, and Alzheimer's disease that causes behavioral disturbances $[19,20]$. SFAs negatively affects the brain functions and increases the risk of neurological diseases [21].

Few studies have investigated the association between dietary fat quality (DFQ) and anxiety disorder. Some studies have focused on the consumption of $n$-3 PUFAs such as docosapentaenoic acid (DPA), EPA, DHA, alphalinolenic acid (ALA), and their association with anxiety disorder. The results showed an inverse association between intake of these fatty acids and anxiety in adults [22-25]. In addition, higher consumption of fish, which is an important source of $n-3$ PUFAs, was associated with lower psychological disorders such as anxiety [24]. Due to the limitations of available cross-sectional studies, including the inherent weaknesses of design, age, and sex-specific differences and location differences, disparate results were reported. For instance, a prospective study on university graduates showed that dietary intake of $n$-3 PUFAs was not associated with anxiety disorder [26]. Another cross-sectional study in women reported no relationship between the intake of $n-6$ PUFAs and anxiety disorder [24]. Moreover, a cross-sectional study on subjects with current pure anxiety disorder did not find any association between blood $n-6$ PUFAs levels and anxiety disorders [27]. Pure anxiety is generalized anxiety disorder without depression and stress [28]. The results of experimental studies on the effects of $n-3$ PUFAs on anxiety are not also consistent. The results change depending on the administered doses and the type of fatty acids utilized in the trial. For instance, in an experimental study, consumption of $3 \mathrm{~g} /$ day of EPA and DHA in patients with current obsessive-compulsive disorder reduced anxiety disorder [29]. Another experimental study reported that consumption of at least $2000 \mathrm{mg} /$ day $n-3$ PUFAs in adults reduced anxiety disorder [30]. However, a meta-analysis did not show beneficial effects of omega-3 supplementation on the prevention of anxiety symptoms [31].
Dietary intake may differ between countries that makes region and population-specific research of fatty acids' intake and anxiety disorder important. The variability in fat and fatty acids' intakes in various countries has been reported [32]. For instance, mean intake of total fat ranges from 11.1 to $46.2 \%$ E worldwide [33]. These percentages for SFAs and PUFAs are $2.9-20.9 \% \mathrm{E}$, and $2.8-11.3 \% \mathrm{E}$, respectively [33]. Even great differences in regional fat intakes have been reported in Africa, America, Asia, and Europe [32]. In Iran, consumption of total fat is approximately $22 \% \mathrm{E}$, with about $11.3 \% \mathrm{E}$ coming from SFAs [34]. The proportions of MUFAs (6.8\%E) and PUFAs (2.1\%E) are low. Since consumption of fish is very low, vegetable oils represent the major source of $n-3$ PUFAs intake. Furthermore, due to high consumption of hydrogenated cooking fats, the intake of transfatty acids is much higher compared with many Western countries [35].

To the best of our knowledge, the relationship between anxiety disorder and some fatty acids' intake such as MUFAs has not been investigated in human so far. As it was mentioned before, anxiety is more common in women than men. Since women are the major group of people attending healthcare centers and the sample size was not large, we restricted the study to women. Therefore, we aimed to evaluate the association between anxiety score and the DFQ in women.

\section{Materials and methods \\ Participants}

This cross-sectional study was conducted on 326 Iranian women attending healthcare centers of Amol city, from December 2017 to June 2018. Using random sampling method, 5 centers from 17 centers were selected. The frequency of women aged 18-49 years in each center was obtained. Simple sampling method was employed to select the study participants from each health center, using the proportion-to-size approach. The inclusion criteria were having 18 to 49 years of age and body mass index (BMI) $18.5-34.9 \mathrm{~kg} / \mathrm{m}^{2}$. The exclusion criteria were menopause and pregnancy or lactation. Participants with diagnosed diabetes, heart disease, cancer, liver and kidney disease, hypertension, thyroid disorders, epilepsy, multiple sclerosis, depression, anxiety or stress, or drug use were excluded from the study. In addition, subjects who experienced stressful events in the last 6 months, such as divorce, love failure, loss of family, or close friends, adhering to certain diets in the past year, and smoking were not included in the study. The aim of the study was explained to the women, and written informed consent was obtained from all participants. Data were collected from each individual by face-to-face interview. General data including age, marriage status, parity, 
education level, job, family size, and dietary supplement intake were obtained using interview. The study was ethically approved by Ethics Committee of Tehran University of Medical Sciences.

\section{Anthropometric assessment}

Weight was measured with the participant wearing light clothes to the nearest $0.1 \mathrm{~kg}$. Height was measured in standing position, shoulders, and barefoot touching the wall to the nearest $0.5 \mathrm{~cm}$ [36]. Waist circumference (WC) was measured to the nearest $0.5 \mathrm{~cm}$ at the midpoint between the lowest rib and the top of the iliac crest in standing position [37]. Body mass index (BMI) was calculated by dividing weight in kilograms by height in squared meters $\left(\mathrm{kg} / \mathrm{m}^{2}\right)$.

\section{Physical activity assessment}

Physical activity (PA) was measured using the short form of International Physical Activity Questionnaire (IPAQ) [38]. The reliability and validity of this questionnaire was assessed across 12 countries. The Spearman's $\rho$ for the reliability of IPAQ questionnaires has been reported around 0.8 . The criterion validity had a median $\rho$ of about 0.30 , which was similar to other validation studies [39]. Participants reported times spent on strenuous, moderate, and mild physical activity over the past 7 days, and then, the values were multiplied by their metabolic equivalent (MET) quantities and the obtained numbers were summed together to calculate MET/mint/week value.

\section{Anxiety score assessment}

To determine the status of depression, anxiety and stress, the DASS [21 items] questionnaire was used. DASS questionnaire was provided by Lovibond in 1995 [40]. The questionnaire of DASS was validated by Jafari et al. [41] in 783 Iranian medical students in 2017. The Cronbach's alpha for depression, anxiety, and stress scales have been reported $0.86,0.76$, and 0.79 , respectively. In the short form of the DASS questionnaire, for each subscale of depression, anxiety, and stress, seven questions have been presented. Participants were asked to respond to each question based on to what extent that item applied to them during the last week (from 0 to 3: not at all, to some degree, to a considerable degree, and very much, respectively). At the end, the scores on the DASS-21 were multiplied by two to calculate the final score. Based on the total score of anxiety, the subjects were divided into five groups of without anxiety (0-7), mild (8-9), moderate (10-14), severe (15-19), and very severe $(>20)$ anxiety [40]. However, due to the limited number of cases in some groups, similar to another study [42], we simply divided participants into two groups of without anxiety $(<8)$ and with anxiety $(\geq 8)$.

\section{Dietary intake assessment}

Dietary exposure was measured by a validated 168-item semi-quantitative food frequency questionnaire (FFQ). This questionnaire was validated in Iran. The mean energy-adjusted reliability coefficient for nutrient intake was reported 0.6 for women. The ranges of questionnaire validity coefficients were $0.21-0.56$ for protein, $0.37-0.61$ for potassium, $0.38-0.50$ for beta carotene, $0.31-0.95$ for cholesterol, $0.21-0.55$ for retinol, and $0.28-0.38$ for alpha tocopherol) [43].

Participants were asked to report their frequency of consumption of a given serving of each food item during the previous year, on a daily (e.g., bread), weekly (e.g., rice, meat), or monthly (e.g., fish) basis. The reported frequency for each food was converted to daily intake and was analyzed for energy and nutrient intake using the US Department of Agriculture's (USDA) food composition tables [44]. All food intakes were analyzed for energy intake, macronutrients, and micronutrients using Nutritionist 4 software modified for Iranian foods [45]. Participants with energy intake out of predefined limits $(500 \mathrm{kcal} /$ day or $3500 \mathrm{kcal} /$ day) were excluded $(\mathrm{n}=26)$ [46]. We used healthy eating index (HEI-2015) for examining the adherence to the healthy eating guidelines [47]. In this guideline, food is divided into 13 groups: whole fruit, whole fruits without juices, whole vegetables, beans and green vegetables, whole grains, dairy, whole protein foods, seafood dishes and vegetable proteins, fatty acids, refined grains, sodium, added sugars, and SFA. Each component is based on $1000 \mathrm{cal}$. Each component was scored on a scale of $0-5$ or $0-10$. We excluded fatty acids and SFA when calculating the HEI score.

\section{Statistical analysis}

Data analysis was done by Statistical Package for Social Sciences (SPSS) version 22 (SPSS Inc, Chicago). The Kolmogorov-Smirnov test was used to examine the normal distribution of variables. To compare the means of normally distributed variables between participants without anxiety and with anxiety, independent samples t test was used. Chi-square and ANOVA tests were used to determine the relationship between anxiety and qualitative and quantitative variables, respectively. All fatty acids' intake was adjusted for energy intake using the residual method [48]. The relationship between fatty acids' intake and odd ratio (OR) of anxiety was analyzed by simple logistic regression. In addition to the unadjusted analysis (model 1), we used multivariable models to assess the relationship between fatty acids' intake and anxiety (model 2). In model 2, we adjusted for age, parity, job, physical activity [22], and total energy intake. These covariates have been associated with anxiety in the 
present and previous studies [22, 24]. $P$-values less than 0.05 were considered significant.

\section{Results}

Figure 1 shows the participant flow diagram throughout the study. A total of 1000 individuals were invited for participation in the study. Of these, 321 women declined to participate and 353 subjects did not meet eligibility criteria. About 26 individuals were excluded with energy intake out of predefined limits $(500 \mathrm{kcal} /$ day or $3500 \mathrm{kcal} /$ day in women). Finally, 300 participants remained in the study.

The prevalence of mild, moderate, severe, and very severe anxiety was $6 \%, 19.7 \%, 7 \%$, and $5 \%$, respectively. About $62.3 \%$ of participants were also without anxiety. Characteristics of participants with and without anxiety are presented in Table 1. Compared with women without anxiety $(<8)$, participants with anxiety $(\geq 8)$ were more employed $(p$-value $=0.005)$, which had lower parity $(p$-value $=0.04)$, higher intake of SFAs $(p$-value $\leq$ $0.001)$, lower intake of MUFAs $(p$-value $=0.01)$, Oleic acid $(p$-value $=0.001)$, and ALA $(p$-value $\leq 0.001)$. Other variables were not significantly different between the two groups.

Table 2 shows the result of logistic regression analysis for odds of anxiety across the quintuples of energyadjusted dietary fatty acids' intake. An increase in the OR for anxiety was observed across the quintuples of SFAs (OR 3.25; 95\% CI 1.51-7.02; $p$-trend $=0.001$ ). In addition, participants included in the highest quintuple of SFAs presented higher OR for anxiety (OR 3.25; 95\% CI $1.51-7.02 ; p=0.003)$ as compared with participants in the first quintuple. Moreover, significant inverse associations were found between anxiety and intake of MUFAs (OR 0.37; 95\% CI 0.17-0.80; $p$-trend $=0.02$ ), oleic acid

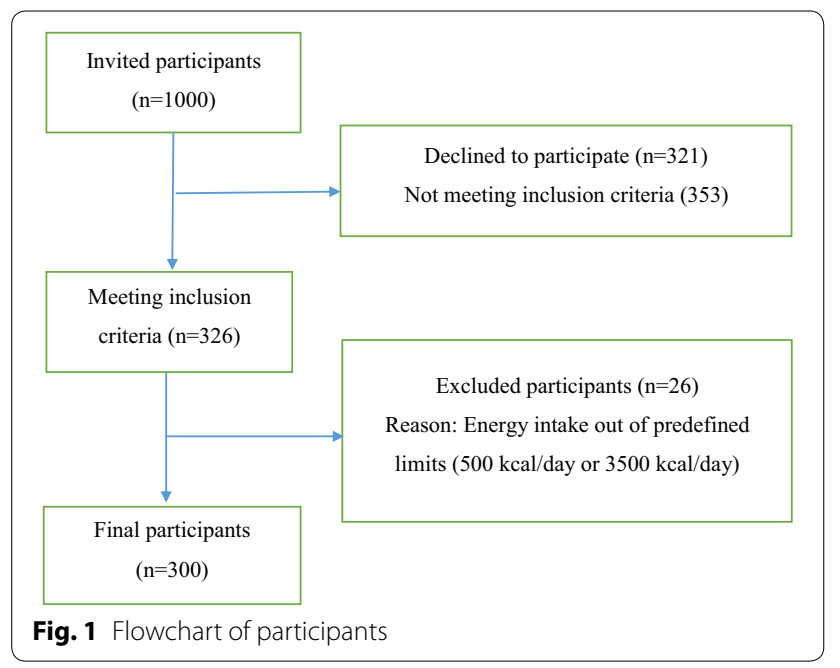

(OR 0.28; 95\% CI 0.13-0.60; $p$-trend $=0.001)$, ALA (OR 0.08 ; 95\% CI $0.03-0.21 ; p$-trend $\leq 0.001)$, and $n-3: n-6$ PUFAs ratio (OR 0.6; 95\% CI 0.31-1.37; $p$-trend $=0.02$ ). In addition, those participants who were included in the third quintuple of PUFAs (OR 0.41; 95\% CI 0.19-0.89; $p=0.02$ ) and $n$-3 PUFAs (OR $0.41 ; 95 \%$ CI $0.18-0.92$; $p=0.03$ ) had lower OR as compared with participants in the first quintuple. We found no significant association between anxiety and intake of total fat (OR 1.46; 95\% CI $0.67-3.15 ; p$-trend $=0.1$ ), dietary cholesterol (OR 2.04; 95\% CI 0.96-4.32; $p$-trend=0.1), DHA (OR 0.47; 95\% CI 0.22-1.02; $p$-trend $=0.2$ ), EPA (OR 0.52; 95\% CI $0.24-1.11 ; p$-trend $=0.2$ ), and $n$-6 PUFAs (OR 1.15 ; 95\% CI 0.54-2.45; $p$-trend $=0.4$ ) (Table 2, Model 1). After adjustment for age, parity, job, physical activity, BMI, and total energy intake, the positive association between anxiety and SFAs remained significant (OR 3.17; 95\% CI 1.43$7.00 ; p$-trend $=0.005$, Model 3 ). In addition, the inverse associations between anxiety and intake of MUFAs (OR 0.15 ; 95\% CI 0.05-0.44; $p$-trend $=0.001$, Model 4 ), oleic acid (OR 0.25; 95\% CI 0.09-0.67; $p$-trend $=0.002$, Model 4), ALA (OR 0.07; 95\% CI 0.02-0.23; $p$-trend <0.001, Model 7), and $n$-3: $n-6$ PUFAs ratio (OR 0.56 ; $95 \%$ CI $0.24-1.03 ; p$-trend $=0.02$, Model 5) remained significant. Furthermore, those participants who were included in the third quintuple of $n-3$ PUFAs presented lower OR for anxiety (OR 0.37; 95\% CI 0.15-0.94; $\mathrm{p}=0.03$ ) as compared with participants in the first quintuple. After adjustment for covariates, we found no association between anxiety and intake of total fat (OR 1.20; 95\% CI $0.56-2.66 ; p$-trend $=0.4$; Model 2), PUFAs (OR 1.49; 95\% CI 0.53-4.14; $p$-trend $=0.1$; Model 5), dietary cholesterol (OR 0.98; 95\% CI 0.39-2.50; $p$-trend $=0.4$; Model 6), DHA (OR 0.59; 95\% CI 0.25-1.40; $p$-trend $=0.6$; Model 7), EPA (OR 0.62; 95\% CI 0.26-1.48; $p$-trend $=0.4$; Model 7), and $n-6$ PUFAs (OR 1.24; 95\% CI 0.38-4.08; $p$-trend $=0.3$; Model 8 ) (Table 2).

\section{Discussion}

In the present study, we investigated the relationship between anxiety disorder and DFQ in women. The result of this study suggested that higher intake of SFAs was associated with increased anxiety score. In addition, intake of MUFAs, oleic acid, ALA, and n-3:n-6 PUFAs ratio was associated with lower odds of anxiety. Our study showed no significant association between intake of DHA, EPA, $n-6$ PUFAs, cholesterol, and total fat with anxiety disorder.

Our study showed that higher SFAs intake was associated with higher anxiety score. Similarly, a randomized crossover-design study in university students showed that SFAs intake is positively related to anxiety score [49]. In our study, a higher intake of MUFAs and oleic acid was 
Table 1 Characteristics of participants across anxiety status

\begin{tabular}{|c|c|c|c|}
\hline Variable & $\begin{array}{l}\text { With anxiety (score } \geq 8 \text { ) } \\
N=113\end{array}$ & $\begin{array}{l}\text { Without anxiety }(\text { score }<8 \text { ) } \\
N=187\end{array}$ & $P$-value ${ }^{a}$ \\
\hline Age $(\text { year })^{b}$ & $30.63 \pm 9.47(18-49)$ & $31.71 \pm 8.56(28-49)$ & 0.3 \\
\hline Educational status ${ }^{c}$ & & & 0.9 \\
\hline Less than diploma & $20(17.7)$ & $34(18.2)$ & \\
\hline Diploma and higher & $93(82.3)$ & $153(81.8)$ & \\
\hline Marital status ${ }^{c}$ & & & 0.058 \\
\hline Single & $42(37.2)$ & $50(26.7)$ & \\
\hline Married & $71(62.8)$ & $137(73.3)$ & \\
\hline$J a b^{c}$ & & & 0.005 \\
\hline House wife & $59(52.2)$ & $128(68.4)$ & \\
\hline Employed & $54(47.8)$ & $59(31.6)$ & \\
\hline Dietary supplement intake ${ }^{c}$ & & & 0.6 \\
\hline Yes & $54(47.8)$ & $84(44.9)$ & \\
\hline No & $59(52.2)$ & $103(55.1)$ & \\
\hline Total PAC (MET/min/week) & & & 0.06 \\
\hline Low & $63(55.8)$ & $116(62)$ & \\
\hline Moderate & $23(20.4)$ & $46(24.6)$ & \\
\hline High & $27(23.9)$ & $25(13.4)$ & \\
\hline Family size ${ }^{b}$ & $3.69 \pm 0.93$ & $3.58 \pm 0.95$ & 0.3 \\
\hline Parity $^{b}$ & $0.98 \pm 1.14$ & $1.21 \pm 1.21$ & 0.04 \\
\hline Total energy intake (kcal/day) & $2509 \pm 589$ & $2481 \pm 518$ & 0.6 \\
\hline $\mathrm{HEl}^{\mathrm{b}}$ & $46.92 \pm 5.95$ & $46.93 \pm 7.16$ & 0.9 \\
\hline \multicolumn{4}{|l|}{ Anthropometric measures } \\
\hline Height $^{b}$ & $161.38 \pm 5.65$ & $161.10 \pm 11.96$ & 0.8 \\
\hline Body weight (kg) & $66.38 \pm 10.88$ & $68.84 \pm 10.45$ & 0.053 \\
\hline WC (cm) & $84.09 \pm 11.54$ & $85.63 \pm 10.68$ & 0.2 \\
\hline $\operatorname{BMl}\left(\mathrm{km} / \mathrm{m}^{2}\right)$ & $26.43 \pm 6.92$ & $26.59 \pm 3.82$ & 0.7 \\
\hline \multicolumn{4}{|l|}{ Energy-adjusted dietary intake/d $\mathrm{d}^{\mathrm{d}}$} \\
\hline Total fat (g) & $84.69 \pm 17.36$ & $82.77 \pm 13.24$ & 0.2 \\
\hline SFAs (g) & $27.34 \pm 6.34$ & $24.69 \pm 4.48$ & $<0.001$ \\
\hline MUFAs (g) & $25.19 \pm 4.40$ & $26.45 \pm 4.48$ & 0.01 \\
\hline Oleic acid (g) & $22.34 \pm 4.13$ & $24.00 \pm 4.32$ & 0.001 \\
\hline PUFAs (g) & $15.26 \pm 3.74$ & $16.12 \pm 4.39$ & 0.08 \\
\hline Dietary cholesterol (mg) & $274.8 \pm 71.8$ & $265.2 \pm 66.7$ & 0.2 \\
\hline$n-3$ PUFAs (g) & $0.90 \pm 0.35$ & $0.89 \pm 0.32$ & 0.8 \\
\hline ALA (g) & $1.04 \pm 0.35$ & $1.39 \pm 0.51$ & $<0.001$ \\
\hline $\mathrm{DHA}(\mathrm{g})$ & $0.09 \pm 0.10$ & $0.10 \pm 0.11$ & 0.3 \\
\hline EPA (g) & $0.02 \pm 0.03$ & $0.03 \pm 0.03$ & 0.3 \\
\hline n-6 PUFAs (g) & $8.82 \pm 4.01$ & $8.46 \pm 3.82$ & 0.4 \\
\hline$n-3: n-6$ PUFAs & $0.10 \pm 0.02$ & $0.11 \pm 0.03$ & 0.3 \\
\hline
\end{tabular}

Physical activity: low (less than $600 \mathrm{MET} / \mathrm{min} /$ week), moderate (600-3000 MET/min/week), and high (more than 3000 MET/min/week)

HEI Healthy eating index, WC Waist circumference, BMI body mass index, PA physical activity, MET metabolic equivalent, SFAs saturated fatty acids, MUFAs monounsaturated fatty acids, PUFAs polyunsaturated fatty acids, ALA alpha-linolenic acid, DHA docosahexaenoic acid, EPA eicosapentaenoic acids

a Chi-square test

b Mean and standard deviation for quantitative variables

c Number (\%) for qualitative variables

d Independent $t$ test 
Table 2 Odds ratio (OR) and 95\% confidence intervals (Cls) for anxiety across the quintuples (Q) of energy-adjusted dietary fatty acid intake

\begin{tabular}{|c|c|c|c|c|c|c|}
\hline & $\begin{array}{l}\text { Q1 } \\
(n=60)\end{array}$ & $\begin{array}{l}\text { Q2 } \\
(n=60)\end{array}$ & $\begin{array}{l}\mathrm{Q3} \\
(n=60)\end{array}$ & $\begin{array}{l}\mathrm{Q} 4 \\
(n=60)\end{array}$ & $\begin{array}{l}\text { Q5 } \\
(n=60)\end{array}$ & $p$-trend \\
\hline Total fat (non-case/case) & $(43 / 17)$ & $(39 / 21)$ & $(35 / 25)$ & $(32 / 28)$ & $(38 / 22)$ & \\
\hline Model 1 & 1.00 & $1.36(0.62-2.94)$ & $1.80(0.84-3.86)$ & $2.21(1.03-4.71)$ & $1.46(0.67-3.15)$ & 0.1 \\
\hline$P$-value & & 0.4 & 0.1 & 0.1 & 0.4 & \\
\hline Model 2 & 1.00 & $1.23(0.55-2.73)$ & $1.77(0.79-3.96)$ & $1.81(0.82-3.98)$ & $1.20(0.56-2.66)$ & 0.4 \\
\hline$P$-value & & 0.6 & 0.1 & 0.1 & 0.6 & \\
\hline SFAs (non-case/case) & $(44 / 16)$ & $(43 / 17)$ & $(35 / 25)$ & $(37 / 23)$ & $(28 / 32)$ & \\
\hline Model 1 & 1.00 & $1.08(0.48-2.42)$ & $1.96(0.91-4.23)$ & $1.66(0.76-3.60)$ & $3.25(1.51-7.02)$ & 0.001 \\
\hline$P$-value & & 0.8 & 40.08 & 0.1 & 0.003 & \\
\hline Model 3: model $2+$ MUFAs, PUFAs, Trans & 1.00 & $1.36(0.59-3.12)$ & $2.12(0.96-4.69)$ & $1.66(0.75-3.70)$ & $3.17(1.43-7.00)$ & 0.005 \\
\hline$P$-value & & 0.4 & 0.06 & 0.2 & 0.004 & \\
\hline MUFAs (non-case/case) & $(29 / 31)$ & $(38 / 22)$ & $(39 / 21)$ & $(39 / 22)$ & $(42 / 17)$ & \\
\hline Model 1 & 1.00 & $0.54(0.26-1.12)$ & $0.50(0.24-1.04)$ & $0.52(0.25-1.09)$ & $0.37(0.17-0.80)$ & 0.02 \\
\hline$P$-value & & 0.6 & 0.6 & 0.02 & 0.2 & \\
\hline Model 4: model $2+$ SFAs, PUFAs, Trans & 1.00 & $0.41(0.19-0.90)$ & $0.36(0.16-0.82)$ & $0.34(0.15-0.77)$ & $0.15(0.05-0.44)$ & 0.001 \\
\hline$P$-value & & 0.02 & 0.01 & 0.01 & 0.001 & \\
\hline Oleic acid (non-case/case) & $(25 / 35)$ & $(38 / 22)$ & $(40 / 20)$ & $(41 / 19)$ & $(43 / 17)$ & \\
\hline Model 1 & 1.00 & $0.42(0.20-0.88)$ & $0.34(0.16-0.73)$ & $0.33(0.15-0.69)$ & $0.28(0.13-0.60)$ & 0.001 \\
\hline$P$-value & & 0.02 & 0.005 & 0.004 & 0.001 & \\
\hline Model 4: model $2+$ SFAs, PUFAs, Trans & 1.00 & $0.43(0.20-0.92)$ & $0.33(0.15-0.72)$ & $0.28(0.12-0.64)$ & $0.25(0.09-0.67)$ & 0.002 \\
\hline$P$-value & & 0.03 & 0.006 & 0.002 & 0.006 & \\
\hline PUFAs (non-case/case) & $(32 / 28)$ & $(39 / 21)$ & $(44 / 16)$ & $(30 / 30)$ & $(42 / 18)$ & \\
\hline Model 1 & 1.00 & $0.61(0.29-1.28)$ & $0.41(0.19-0.89)$ & $1.14(0.55-2.34)$ & $0.49(0.23-1.03)$ & 0.3 \\
\hline$P$-value & & 0.1 & 0.02 & 0.7 & 0.06 & \\
\hline Model 5: model 2+SFAs, MUFAs, Trans & 1.00 & $0.96(0.41-2.23)$ & $1.71(0.72-4.05)$ & $2.35(0.99-5.58)$ & $1.49(0.53-4.14)$ & 0.1 \\
\hline$P$-value & & 0.9 & 0.2 & 0.052 & 0.4 & \\
\hline Dietary cholesterol (non-case/case) & $(42 / 18)$ & $(34 / 26)$ & $(41 / 19)$ & $(38 / 22)$ & $(32 / 28)$ & \\
\hline Model 1 & 1.00 & $1.78(0.84-3.78)$ & $1.08(0.49-2.34)$ & $1.35(0.63-2.89)$ & $2.04(0.96-4.32)$ & 0.1 \\
\hline$P$-value & & 0.1 & 0.8 & 0.4 & 0.06 & \\
\hline Model 6: model 2+ SFAs, PUFAs, MUFAs, Trans & 1.00 & $1.91(0.83-4.41)$ & $0.92(0.38-2.22)$ & $0.93(0.38-2.20)$ & $0.98(0.39-2.50)$ & 0.4 \\
\hline$P$-value & & 0.2 & 0.5 & 0.6 & 0.7 & \\
\hline n-3 PUFAs (non-case/case) & $(36 / 24)$ & $(35 / 25)$ & $(47 / 13)$ & $(32 / 28)$ & $(37 / 23)$ & \\
\hline Model 1 & 1.00 & $1.07(0.51-2.21)$ & $0.41(0.18-0.92)$ & $1.31(0.63-2.70)$ & $0.93(0.44-1.94)$ & 0.9 \\
\hline$P$-value & & 0.8 & 0.03 & 0.4 & 0.8 & \\
\hline Model 7: model $2+$ SFAs, MUFAs, Trans, $n-6$ & 1.00 & $1.05(0.46-2.40)$ & $0.37(0.15-0.94)$ & $0.92(0.38-2.26)$ & $0.66(0.21-2.04)$ & 0.4 \\
\hline$P$-value & & 0.8 & 0.03 & 0.8 & 0.4 & \\
\hline ALA (non-case/case) & $(24 / 36)$ & $(35 / 25)$ & $(28 / 32)$ & $(46 / 14)$ & $(54 / 6)$ & \\
\hline Model 1 & 1.00 & $0.44(0.21-0.92)$ & $0.73(0.35-1.51)$ & $0.18(0.08-0.40)$ & $0.08(0.03-0.21)$ & $<0.001$ \\
\hline$P$-value & & 0.02 & 0.3 & $<0.001$ & $<0.001$ & \\
\hline Model 7: model $2+$ SFAs, MUFAs, Trans, $n-6$ & 1.00 & $0.34(0.15-0.79)$ & $0.59(0.25-1.39)$ & $0.14(0.05-0.37)$ & $0.07(0.02-0.23)$ & $<0.001$ \\
\hline$P$-value & & 0.6 & 0.6 & 0.1 & $<0.001$ & \\
\hline DHA (non-case/case) & $(34 / 26)$ & $(38 / 22)$ & $(39 / 21)$ & $(32 / 28)$ & $(44 / 16)$ & \\
\hline Model 1 & 1.00 & $0.75(0.36-1.57)$ & $0.70(0.33-1.47)$ & $1.14(0.55-2.35)$ & $0.47(0.22-1.02)$ & 0.2 \\
\hline$P$-value & & 0.4 & 0.3 & 0.7 & 0.05 & \\
\hline Model 7: model $2+$ SFAs, MUFAs, Trans, $n-6$ & 1.00 & $0.77(0.34-1.73)$ & $0.94(0.41-2.15)$ & $1.29(0.57-2.90)$ & $0.59(0.25-1.40)$ & 0.6 \\
\hline P-value & & 0.5 & 0.8 & 0.5 & 0.2 & \\
\hline EPA (non-case/case) & $(33 / 27)$ & $(39 / 21)$ & $(37 / 23)$ & $(36 / 24)$ & $(42 / 18)$ & \\
\hline Model 1 & 1.00 & $0.65(0.31-1.37)$ & $0.76(0.36-1.57)$ & $0.81(0.39-1.68)$ & $0.52(0.24-1.11)$ & 0.2 \\
\hline$P$-value & & 0.2 & 0.4 & 0.5 & 0.09 & \\
\hline
\end{tabular}


Table 2 (continued)

\begin{tabular}{|c|c|c|c|c|c|c|}
\hline & $\begin{array}{l}\text { Q1 } \\
(n=60)\end{array}$ & $\begin{array}{l}\text { Q2 } \\
(n=60)\end{array}$ & $\begin{array}{l}\text { Q3 } \\
(n=60)\end{array}$ & $\begin{array}{l}\mathrm{Q} 4 \\
(n=60)\end{array}$ & $\begin{array}{l}\text { Q5 } \\
(n=60)\end{array}$ & $p$-trend \\
\hline Model 7: model $2+$ SFAs, MUFAs, Trans, $n-6$ & 1.00 & $0.63(0.27-1.44)$ & $0.93(0.41-2.12)$ & $0.78(0.35-1.75)$ & $0.62(0.26-1.48)$ & 0.4 \\
\hline$P$-value & & 0.2 & 0.8 & 0.5 & 0.2 & \\
\hline n-6 PUFAs (non-case/case) & $(40 / 20)$ & $(40 / 20)$ & $(35 / 25)$ & $(34 / 26)$ & $(38 / 22)$ & \\
\hline Model 1 & 1.00 & $1.00(0.46-2.13)$ & $1.42(0.68-3.00)$ & $1.52(0.72-3.20)$ & $1.15(0.54-2.45)$ & 0.4 \\
\hline$P$-value & & 1.0 & 0.3 & 0.2 & 0.7 & \\
\hline Model 8: model $2+$ SFAs, MUFAs, Trans, $n-3$ & 1.00 & $0.89(0.37-2.10)$ & $1.56(0.65-3.71)$ & $1.61(0.65-4.00)$ & $1.24(0.38-4.08)$ & 0.3 \\
\hline$P$-value & & 0.7 & 0.3 & 0.2 & 0.7 & \\
\hline n-3:n-6 (non-case/case) & $(34 / 26)$ & $(33 / 27)$ & $(33 / 27)$ & $(47 / 13)$ & $(40 / 20)$ & \\
\hline Model 1 & 1.00 & $1.07(0.5-2.2)$ & $1.07(0.5-2.2)$ & $0.3(0.16-0.80)$ & $0.6(0.31-1.37)$ & 0.02 \\
\hline$P$-value & & 0.85 & 0.85 & 0.01 & 0.26 & \\
\hline Model 5: model $2+$ SFAs, MUFAs, Trans & 1.00 & $0.97(0.42-2.23)$ & $0.94(0.41-2.17)$ & $0.36(0.15-0.88)$ & $0.56(0.24-1.03)$ & 0.02 \\
\hline$P$-value & & 0.9 & 0.9 & 0.02 & 0.1 & \\
\hline
\end{tabular}

Model 1: Crude

Model 2 Adjusted for age, physical activity, total energy intake, job, body mass index, and parity

SFAs saturated fatty acids, MUFAs monounsaturated fatty acids, PUFAs polyunsaturated fatty acids, ALA alpha-linolenic acid, DHA docosahexaenoic acid, EPA eicosapentaenoic acids

related to lower anxiety score. To the best of our knowledge, no study has reported the association of MUFAs with anxiety disorder. In addition, we showed an inverse association between n-3:n-6 PUFAs ratio and anxiety score. Similar to our study results, a prospective cohort study showed a positive significant association between lower ratio of $n-3: n-6$ PUFAs and anxiety disorder [50]. Although no association was found between DHA, EPA, and $n-6$ PUFAs with anxiety score in the present study, the data from some cross-sectional studies have shown an inverse relationship between intake of DHA and EPA with anxiety in adults [22-24]. In addition, some experimental studies have shown that intake of EPA and DHA reduces anxiety disorder $[29,51]$. However, a prospective study did not find any relationship between intake of $n-3$ PUFAs and anxiety disorder [26]. In addition, a crosssectional study showed that dietary intake of $n-6$ PUFAs is not related with anxiety [24]. Contrary to our findings, an experimental study on adults showed beneficial effect of low-fat diet in comparison with a high-fat diet on psychological mood states [52]. The disparity between the findings might be explained by the differences in study design, sample size, characteristics of study participants, and geographic differences. Some biological mechanisms explain the effect of fatty acids in psychiatric disorders; these include regulation of corticotropin-releasing factor, the hypothalamic-pituitary-adrenocortical axis, increased serotonergic neurotransmission, alterations in dopaminergic function, and improved cerebral blood flow [53-55]. In addition, fatty acids have an effect on receptor function, signal transmission, and neurotransmitter reuptake [26]. A few studies have examined the relationship between fatty acids' intake and anxiety, especially in a general population. The current study was adjusted for several important confounders that are known to affect anxiety disorder and DFQ. In addition, women in our study were not informed of their anxiety status. When individuals are aware of their anxiety disorder, they might change their food intake or dietary intake report. However, the study has some limitations. First, FFQ has a potential recall bias. Respondents are requested to report their intake retrospectively, which may affect their reporting. Recall bias increases with recall periods longer than 7 days [56]. The FFQ used in the present study was excessively long and required recall of up to 1 year, which may affect the report of dietary intake in the participants. In addition, it is difficult for respondents to answer the questions regarding usual frequency of intake and usual portion size, and are thus prone to measurement error [56]. Second, the study design was cross-sectional, which cannot interpret a cause-and-effect relationship. Third, it is possible that experiencing anxiety might have resulted in lifestyle modification including lower dietary intake or altered dietary choices, which could result in potential bias. Fourth, regardless of adjusting for many confounding variables in the analysis, residual confounding together with unmeasured confounders may have affected the results. Fifth, as the study population was women who attended the healthcare centers, we cannot generalize our results to all women in this age group. In addition, the findings might not be generalized to men and populations with ethnic and cultural differences. 


\section{Conclusion}

Based on the results of the present study, an inverse association was found between intakes of MUFAs, oleic acid, ALA, and n-3:n-6 PUFAs ratio with odds of anxiety. In addition, higher intake of SFAs was associated with higher anxiety score. The study analysis showed that overall DFQ may be important in anxiety disorder. These results may help to develop nutritional interventions and dietary guidelines to prevent or reduce anxiety in women. Nevertheless, experimental studies are required to evaluate the effect of DFQ on anxiety disorder.

\section{Acknowledgements}

We thank authorities of the International Campus of Tehran University of Medical Sciences and the department of Community Nutrition for their support during the design of this study. We also extend our profound gratitude to all study participants who made it possible for us to obtain data for this study.

\section{Authors' contributions}

SBS has made substantial contributions to conception and design, and has been involved in drafting of the manuscript. GS has made substantial contributions to the design, revised the manuscript critically, and given the final approval of the version to be submitted. MS has made substantial contributions to conception and revised the manuscript. FS has made substantial contributions to conception and design. ARF has contributed greatly in offering advice on statistical design and analysis. All authors read and approved the final manuscript.

\section{Funding}

This project was supported by the International Campus of Tehran University of Medical Sciences under Grant Number 9513475002.

\section{Data availability statement}

The data used to support the findings of this study are available from the corresponding author.

\section{Ethics approval and consent to participate}

The study protocol was approved by the Ethics Committee of Tehran University of Medical Sciences, Tehran, Iran (IR.TUMS.VCR.REC.1397.146). The aim of the study was explained to the women, and written informed consent was obtained from all participants.

\section{Competing interests}

The authors declare that they have no competing interests.

\section{Author details \\ ${ }^{1}$ Department of Community Nutrition, School of Nutritional Sciences and Die- tetics, Tehran University of Medical Sciences, Hojatdost street, Naderi street, Keshavarz Blv., Tehran, Iran. ${ }^{2}$ Non-Communicable Diseases Research Center, Alborz University of Medical Sciences, Karaj, Iran. ${ }^{3}$ Chronic Diseases Research Center, Endocrinology and Metabolism Population Sciences Institute, Tehran University of Medical Sciences, Tehran, Iran.}

Received: 9 October 2019 Accepted: 10 February 2020 Published online: 26 February 2020

\section{References}

1. WHO (The World Health Organization). Depression. https://www.who.int/ mediacentre/factsheets/fs369/en/. Accessed June 2017.

2. Rosenbaum S, Schuch F, Veronese N, Stubbs B, Lahti J, Firth J, et al. Physical activity and anxiety: a perspective from the World Health Survey. J Affect Disord. 2016;208:545-52.
3. Wittchen HU, Zhao S, Kessler RC, Eaton WW. DSM-III-R generalized anxiety disorder in the national comorbidity survey. Arch Gen Psychiatry. 1994;51(5):355-64.

4. Noorbala AA, Faghihzadeh S, Kamali K, Yazdi SAB, Hajebi A, Mousavi MT, et al. Mental health survey of the iranian adult population in 2015. Arch Iran Med. 2017;20(3):128-34.

5. Hendriks SM, Spijker J, Licht CMM, Beekman ATF, Hardeveld F, De Graaf R, et al. Disability in anxiety disorders. J Affect Disord. 2014;166:227-33.

6. Scott KM, Bruffaerts R, Tsang A, Ormel J, Alonso J, Angermeyer MC, et al. Depression-anxiety relationships with chronic physical conditions: results from the World Mental Health surveys. J Affect Disord. 2007;103(1-3):113-20

7. Goodwin RD, Stein MB. Peptic ulcer disease and neuroticism in the United States adult population. Psychother Psychosom. 2003;72(1):10-5.

8. McWilliams LA, Goodwin RD, Cox BJ. Depression and anxiety associated with three pain conditions: results from a nationally representative sample. Pain. 2004;111(1-2):77-83.

9. Simon NM, Blacker D, Korbly NB, Sharma SG, Worthington JJ, Otto MW, et al. Hypothyroidism and hyperthyroidism in anxiety disorders revisited: new data and literature review. J Affect Disord. 2002;69(1-3):209-17.

10. Sartorius N, Üstün TB, Lecrubier Y, Wittchen HU. Depression comorbid with anxiety: results from the WHO study on psychological disorders in primary health care. Br J Psychiatry. 1996;168(SUPP.30):38-433.

11. Walters V. Stress, anxiety and depression: women's accounts of their health problems. Soc Sci Med. 1993;36(4):393-402

12. Brown HA, Murphy RC. Working towards an exegesis for lipids in biology. Nat Chem Biol. 2009;5:602-6.

13. Gupta A, Petkar SB, Jadhav AA, Dubey V. Study of lipid derangement in pyschiatric disorder. Ind Med Gaz. 2013;(July):253-6.

14. Chen HF, Su HM. Exposure to a maternal n-3 fatty acid-deficient diet during brain development provokes excessive hypothalamic-pituitaryadrenal axis responses to stress and behavioral indices of depression and anxiety in male rat offspring later in life. J Nutr Biochem. 2013;24(1):70-80

15. Bazan NG. Lipid signaling in neural plasticity, brain repair, and neuroprotection. Mol Neurobiol. 2005;32:89-103.

16. Lin PY, Huang SY, Su KP. A meta-analytic review of polyunsaturated fatty acid compositions in patients with depression. Biol Psychiatry. 2010;68(2):140-7.

17. Alemany R, Navarro MA, Vögler O, Perona JS, Osada J, Ruiz-Gutiérrez V. Olive oils modulate fatty acid content and signaling protein expression in apolipoprotein e knockout mice brain. Lipids. 2010;45(1):53-61.

18. Maulucci G, Cohen O, Daniel B, Sansone A, Petropoulou PI, Filou S, et al. Fatty acid-related modulations of membrane fluidity in cells: detection and implications. Free Radic Res. 2016;50(sup1):S40-50.

19. Kumar VB, Vyas K, Buddhiraju M, Alshaher M, Flood JF, Morley JE. Changes in membrane fatty acids and delta-9 desaturase in senescence accelerated (SAMP8) mouse hippocampus with aging. Life Sci. 1999;65(16):1657-62.

20. Kim E, Ko HJ, Jeon SJ, Lee S, Lee HE, Kim HN, et al. The memory-enhancing effect of erucic acid on scopolamine-induced cognitive impairment in mice. Pharmacol Biochem Behav. 2016;142:85-90.

21. Barnard ND, Bunner AE, Agarwal U. Saturated and trans fats and dementia: a systematic review. Neurobiol Aging. 2014;35(SUPPL.2):S65-73.

22. Natacci L, Marchioni DM, Goulart AC, Nunes MA, Moreno AB, Cardoso LO, et al. Omega 3 consumption and anxiety disorders: a cross-sectional analysis of the brazilian longitudinal study of adult health (ELSA-Brasil). Nutrients. 2018;10(6):663.

23. Ross BM. Omega-3 polyunsaturated fatty acids and anxiety disorders. Prostaglandins Leukot Essent Fat Acids. 2009;81(5-6):309-12.

24. Jacka FN, Pasco JA, Williams LJ, Meyer BJ, Digger R, Berk M. Dietary intake of fish and PUFA, and clinical depressive and anxiety disorders in women. Br J Nutr. 2013;109(11):2059-66.

25. Su KP, Matsuoka Y, Pae CU. Omega-3 polyunsaturated fatty acids in prevention of mood and anxiety disorders. Clin Psychopharmacol Neurosci. 2015;13(2):129-37.

26. Sanchez-Villegas A, Henríquez P, Figueiras A, Ortuño F, Lahortiga F, Martínez-González MA. Long chain omega-3 fatty acids intake, fish consumption and mental disorders in the SUN cohort study. Eur J Nutr. 2007;46(6):337-46. 
27. Thesing CS, Bot M, Milaneschi Y, Giltay EJ, Penninx BWJH. Omega-3 and omega- 6 fatty acid levels in depressive and anxiety disorders. Psychoneuroendocrinology. 2018;87:53-62

28. Kessler RC, DuPont RL, Berglund P, Wittchen HU. Impairment in pure and comorbid generalized anxiety disorder and major depression at 12 months in two national surveys. Am J Psychiatry. 1999;156(12):1915-23.

29. Fux M, Benjamin J, Nemets B. A placebo-controlled cross-over trial of adjunctive EPA in OCD. J Psychiatr Res. 2004;38(3):323-5.

30. Su K-P, Tseng P-T, Lin P-Y, Okubo R, Chen T-Y, Chen Y-W, et al. Association of use of omega-3 polyunsaturated fatty acids with changes in severity of anxiety symptoms. JAMA Netw Open. 2018;1(5):e182327.

31. Deane $K H O$, Jimoh OF, Biswas $P, O^{\prime}$ Brien A, Hanson S, Abdelhamid AS, et al. Omega-3 and polyunsaturated fat for prevention of depression and anxiety symptoms: systematic review and meta-analysis of randomised trials. Br J Psychiatry. 2019;24:1-8.

32. Elmadfa I, Kornsteiner M. Dietary fat intake-a global perspective. Ann Nutr Metab. 2009;54(SUPPL. 1):8-14.

33. Harika RK, Eilander A, Alssema M, Osendarp SJM, Zock PL. Intake of fatty acids in general populations worldwide does not meet dietary recommendations to prevent coronary heart disease: a systematic review of data from 40 countries. Ann Nutr Metab. 2013;63(3):229-38.

34. Kimiagar SM, Ghaffarpour M, Houshiar-Rad A, Hormozdyari H, Zellipour L. Food consumption pattern in Iran and relation to coronary heart diseases. East Mediterr Health J. 1998;4:539-47.

35. Mozaffarian D, Abdollahi M, Campos H, HoushiarRad A, Willett WC. Consumption of trans fats and estimated effects on coronary heart disease in Iran. Eur J Clin Nutr. 2007;61(8):1004-100.

36. Lohman TJ, Roache AF, Martorell R. Anthropometric standardization reference manual. Med Sci Sport Exerc. 1992;24(8):952.

37. Esmaili H, Bahreynian M, Qorbani M, Motlagh ME, Ardalan G, Heshmat R, et al. Prevalence of general and abdominal obesity in a nationally representative sample of Iranian children and adolescents: the CASPIAN-IV study. Iran J Pediatr. 2015;25(3):27-31.

38. IPAQ Group. Guidelines for data processing and analysis of the international physical activity questionnaire (IPAQ) — short and long forms. Ipaq. 2005;(November):1-15.

39. Craig CL, Marshall AL, Sjöström M, Bauman AE, Booth ML, Ainsworth BE, et al. International physical activity questionnaire: 12-country reliability and validity. Med Sci Sports Exerc. 2003;35(8):1381-95.

40. Lovibond PF, Lovibond SH. The structure of negative emotional states: comparison of the Depression Anxiety Stress Scales (DASS) with the Beck Depression and Anxiety Inventories. Behav Res Ther. 1995:33(3):335-43.

41. Jafari P, Nozari F, Ahrari F, Bagheri Z. Measurement invariance of the Depression Anxiety Stress Scales-21 across medical student genders. Int J Med Educ. 2017:8:116-22.

42. Liu WJ, Musa R, Chew TF, Lim CTS, Morad Z, Bujang MA. DASS21: a useful tool in the psychological profile evaluation of dialysis patients. Am J Med Sci. 2018;355(4):322-30.
43. Mirmiran P, Hosseini F, Mehrabi Y, Hedayati M, Azizi F. Reliability and relative validity of an FFQ for nutrients in the Tehran lipid and glucose study. Public Health Nutr. 2010:13(5):654-62.

44. Sánchez-Villegas A, Verberne L, de Irala J, Ruíz-Canela M, Toledo E, SerraMajem $\mathrm{L}$, et al. Dietary fat intake and the risk of depression: the SUN project. PLOS ONE ONE. 2011;6(1):e16268.

45. Ghaffarpour M, Houshiar-Rad A, KianfarH H. The manual for household measures, cooking yields factors and edible portion of foods. 1999, pp. $1-46$.

46. Banna JC, McCrory MA, Fialkowski MK, Boushey C. Examining plausibility of self-reported energy intake data: considerations for method selection. Front Nutr. 2017;4(September):1-6.

47. Overview \& Background of The Healthy Eating Index. National Cancer Institute. 2015. https://epi.grants.cancer.gov/hei/. Accessed Dec 2017.

48. Willett WC, Howe R. Adjustmentfor total energyintake in epidemiologic studies 1-3. Am J Clin Nutr. 1220S;65(Suppl):1220S-S12281228.

49. Lindseth $G$, Petros T. Neurobehavioral effects of consuming dietary fatty acids. Biol Res Nurs. 2016;18(5):573-81.

50. Liu JJ, Galfalvy HC, Ph D, Cooper TB, Maria A, Grunebaum MF, et al. Omega-3 polyunsaturated fatty acid status in major depression with comorbid anxiety disorders. J Clin Psychiatry. 2013;74(7):732-8.

51. Appleton KM, Grippo AJ, Beltz TG, Johnson AK. Consumption of a high n-3 polyunsaturated fatty acid diet during gradual mild physiological stress in rats. Prostaglandins Leukot Essent Fat Acids. 2015;95:11-8.

52. Brinkworth GD. Long-term effects of a very low-carbohydrate diet and a low-fat diet on mood and cognitive function. Arch Intern Med. 2009:169(20):1873.

53. Freeman MP, Hibbeln JR, Wisner KL. Omega-3 fatty acids: evidence basis for treatment and future research in psychiatry. 1955

54. Hibbeln JR, Linnoila M, Umhau JC, Rawlings R, George DT, Salem N. Essential fatty acids predict metabolites of serotonin and dopamine in cerebrospinal fluid among healthy control subjects, and early- and lateonset alcoholics. Biol Psychiatry. 1998:44(4):235-42.

55. Kodas E, Galineau L, Bodard S, Vancassel S, Guilloteau D, Besnard JC, et al. Serotoninergic neurotransmission is affected by $n-3$ polyunsaturated fatty acids in the rat. J Neurochem. 2004;89(3):695-702.

56. Coates J, Colaiezzi B, Fiedler J, Wirth J-, Lividini K-, B R. Applying dietary assessment methods for food fortification and other nutrition programś. Gain Glob Alliance Improv Nutr. 2012;

\section{Publisher's Note}

Springer Nature remains neutral with regard to jurisdictional claims in published maps and institutional affiliations.
Ready to submit your research? Choose BMC and benefit from:

- fast, convenient online submission

- thorough peer review by experienced researchers in your field

- rapid publication on acceptance

- support for research data, including large and complex data types

- gold Open Access which fosters wider collaboration and increased citations

- maximum visibility for your research: over $100 \mathrm{M}$ website views per year

At $\mathrm{BMC}$, research is always in progress.

Learn more biomedcentral.com/submissions 